\title{
ChemComm
}

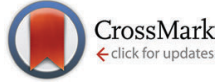

Cite this: Chem. Commun., 2015, 51,279

Received 8th October 2014

Accepted 9th November 2014

DOI: $10.1039 / c 4 c c 07947 g$

www.rsc.org/chemcomm

\section{Organic-free synthesis of layer-like FAU-type zeolites $\uparrow$}

\author{
A. Inayat, ${ }^{\star}$ C. Schneider $\$$ and W. Schwieger
}

The formation of layer-like FAU-type zeolites was facilitated in the absence of any organic template. Instead, the addition of simple inorganic salts turned out to be an effective and easy to handle alternative to organic additives to induce morphological and even structural changes during zeolite crystallisation.

Zeolites are microporous materials $\left(d_{\mathrm{P}}<2 \mathrm{~nm}\right)$ with widespread use as adsorbents, ion exchangers and catalysts. However, their applicability is reduced due to the narrow dimension of the micropores resulting in slow or even restricted mass transport through the zeolite crystal. The reduction of diffusion path lengths through the micropore system proved to greatly enhance the application properties of zeolites. ${ }^{1,2}$ Micropore diffusion path lengths can be reduced either by the introduction of additional intracrystalline meso/macro pores $^{3,4}$ or by reducing the crystal in one dimension (nanosheet morphology), ${ }^{5}$ two dimensions (rod-like morphology) or all three dimensions (nanoparticle morphology). ${ }^{6}$

FAU-type zeolites $\mathrm{X}$ and $\mathrm{Y}$ are industrially very important zeolites $^{7,8}$ which exhibit micropore diameters of $0.74 \mathrm{~nm}$ and conventionally compact (cub)octahedral crystal morphology in the micrometer range. Recently, FAU-type zeolite $\mathrm{X}$ could be synthesized in the form of mesoporous nanosheet assemblies by using the organosilane template TPHAC, ${ }^{9}$ which showed an enhanced transport of organic species (cyclohexane) compared to conventional zeolite $\mathrm{X}$ crystals. ${ }^{10}$ Later on, Khaleel et al. ${ }^{11}$ undertook a very profound electron microscopic investigation of this material and found a small amount of zeolite EMT structure within the FAU-type nanosheets, to which they assigned the growth modifying structural function leading to the openly intergrown cuboctahedral nanosheet assemblies. EMT is the structural

Institute of Chemical Reaction Engineering, University of Erlangen-Nuremberg, Egerlandstrasse 3, D-91058 Erlangen, Germany. E-mail: alexandra.inayat@fau.de; Tel: +4991318527426

$\dagger$ Electronic supplementary information (ESI) available: Additional analytical results from XRD, SEM, elemental analysis, experimental description of analytical procedures and parameters. See DOI: 10.1039/c4cc07947g

\# Current address: Department of Materials Science, WW-4, LKO, University of Erlangen-Nuremberg, Martensstrasse 7, 91058 Erlangen, Germany. twin of FAU, i.e. both are composed of D6R connected sodalite cages, but the location of connections is different, resulting in cubic FAU and hexagonal EMT structure, respectively. There are several types of FAU/EMT intergrowth structures, e.g. ZSM-2, ZSM-3 ECR-30 or CSZ-1, and a plate-like crystal morphology is mentioned at least for ZSM-3. ${ }^{12,13}$

The correlation between the presence of structural twins and layer-like crystal growth has already been employed for the preparation of self-pillared MFI-type zeolite nanosheets by a repetitive branching mechanism. ${ }^{2}$ There, the morphology modifying substances in the synthesis mixture were tetrabutylphosphonium and tetrabutyl-ammonium ions, which eventually induced the formation of small amounts of the twin structure MEL as the MFI-type nanosheet branching points.

However, for technical fabrication of zeolitic nanosheets, the use of organic molecules as morphology modifying agents is a disadvantage due to special handling issues and increased costs.

It has sporadically been reported, that zeolite synthesis in the presence of metal salts can affect the crystal morphology. MFI-type zeolites were synthesized in the presence of $\left[\mathrm{N}\left(\mathrm{CH}_{2} \mathrm{CH}_{3}\right)_{4}\right]_{2}\left[\mathrm{NiCl}_{4}\right]$, $\left[\mathrm{N}\left(\mathrm{CH}_{2} \mathrm{CH}_{3}\right)_{4}\right]_{2}\left[\mathrm{CuCl}_{4}\right],{ }^{14}\left[\mathrm{NEt}_{4}\right]_{2}\left[\mathrm{CoCl}_{4}\right],{ }^{15}\left[\mathrm{NPr}_{4}\right]_{2}\left[\mathrm{MnBr}_{4}\right]^{15}$ and $\left[\mathrm{Zn}\left(\mathrm{NH}_{3}\right)_{4}\right]^{2+} \cdot{ }^{16}$ The aim of these studies was the isomorphous substitution of $\mathrm{Si}$ with the respective metal atoms in order to alter the catalytic properties of the zeolites. On the basis of UV/VIS and FTIR measurements it was claimed that copper, nickel, zinc, manganese and cobalt were indeed integrated as isomorphous substituents into the zeolite structure. As a side effect it was found that the isomorphous substitution with metal cations resulted in MFI-type crystals with either reduced size or increased tendency for twinning and higher aspect ratios. Obviously, some metal cations are able to induce "building faults" in the growing zeolite structure, through which the formation of structural twins is facilitated. ${ }^{2}$ According to the presented SEM images, twinning occurred to be most pronounced for MFI crystals synthesized in the presence of zinc salt, resulting in a star-shaped morphology. ${ }^{16}$ From these reports it seemed that the addition of certain inorganic salts might be a new facile preparative route for zeolites with modified (e.g. nanosheet) morphology. 
The present work demonstrates for the example of zinc nitrate and lithium carbonate, that some simple and easily available inorganic salts are able to direct the growth of FAU-type zeolites into nanosheet morphologies which were up to now (if at all) only observed with organic additives. ${ }^{9,11}$

For the organic-free synthesis of layer-like zeolite X $25.5 \mathrm{~g}$ sodium silicate solution (mass\%: $26.5 \mathrm{SiO}_{2}, 8.3 \mathrm{Na}_{2} \mathrm{O}, 65.2 \mathrm{H}_{2} \mathrm{O}$, Südchemie AG), $1.8 \mathrm{~g} \mathrm{NaOH}$ (97\%, Merck) and $44.7 \mathrm{~g}$ deionised water were mixed at room temperature before $20.1 \mathrm{~g}$ sodium aluminate solution (mass\%: $19.1 \mathrm{Al}_{2} \mathrm{O}_{3}, 19.8 \mathrm{Na}_{2} \mathrm{O}, 61.1 \mathrm{H}_{2} \mathrm{O}$, CWK Bad Köstritz, Germany) and $22.3 \mathrm{~g}$ deionised water were added under vigorous stirring. After the mixture was stirred for 1 hour at $1300 \mathrm{rpm}$, a solution of $3.0 \mathrm{~g}$ zinc nitrate hexahydrate (99\%, Applichem) in $5 \mathrm{ml}$ water was added. The obtained gel with molar composition $1 \mathrm{Al}_{2} \mathrm{O}_{3}: 3.2 \mathrm{Na}_{2} \mathrm{O}: 3 \mathrm{SiO}_{2}: 150 \mathrm{H}_{2} \mathrm{O}: 0.26$ $\mathrm{Zn}^{2+}$ was aged for 20 hours at room temperature and then statically crystallised in a polypropylene bottle at $75{ }^{\circ} \mathrm{C}$ for 25 days in a convection oven. Afterwards the product was isolated by vacuum filtration, washed with deionised water until pH 8 and dried at $75{ }^{\circ} \mathrm{C}$. As a reference, a conventional zeolite $\mathrm{X}$ sample (conv. $\mathrm{X}$ ) was produced in the same way, but in the absence of any salt. Syntheses in the presence of the lithium salt $\mathrm{Li}_{2} \mathrm{CO}_{3}$ (98.5\%, Merck) were performed in an identical manner, but with molar synthesis composition of $1 \mathrm{Al}_{2} \mathrm{O}_{3}: 3.7 \mathrm{Na}_{2} \mathrm{O}: 3 \mathrm{SiO}_{2}: 180 \mathrm{H}_{2} \mathrm{O}: 0.60 \mathrm{Li}^{+}$and crystallisation time of only 28 hours.

The SEM images in Fig. 1 shall give an impression of the particle morphologies obtained in the presence of the different salts in the synthesis mixture for zeolite $\mathrm{X}$.

It is visible that $\mathrm{Zn}^{2+}$ addition led to a pronounced layer-like zeolite morphology with a cuboctahedral layer arrangement very similar to that of $\mathrm{NaX}$ obtained from syntheses with TPHAC $^{9}$ (SEM image also given in Fig. 1). Also the presence of $\mathrm{Li}_{2} \mathrm{CO}_{3}$ led to the formation of well-defined cuboctahedral nanosheet assemblies but with particularly pronounced hexagonal (111) plates in a more skeleton-like arrangement.

Structural analysis by X-ray diffraction (resulting XRD patterns are given in Fig. 2) revealed that the presence of $\mathrm{Li}_{2} \mathrm{CO}_{3}$ during FAU synthesis does not only change the morphology, but also directs the crystallisation towards larger portions of EMT structure, forming the FAU/EMT intergrowth ZSM-3 (reference pdf 38-0317), which was indeed reported to crystallise in lithium containing synthesis gels, though with compositions different from that used in the present study. ${ }^{13,17}$ This XRDvisible presence of FAU/EMT intergrowths is in agreement with the observed more pronounced cuboctahedral morphology of the zeolite particles, which was recently predicted by Khaleel et $a l^{11}$ for increasing contents of the hexagonal EMT twin structure in usually octahedral FAU-type zeolite crystals. The broader reflections in the XRD patterns of this sample are an additional evidence for the increasing amount of stacking faults/twinning in the structure. ${ }^{18}$ On the other hand, the XRD pattern of zeolite crystals obtained from zinc containing synthesis gels is similar to that of the conventional FAU-type zeolite X material (conv. X, reference pdf 12-0228). Although EMT structure (reference pdf 46-0566) is not evident in this

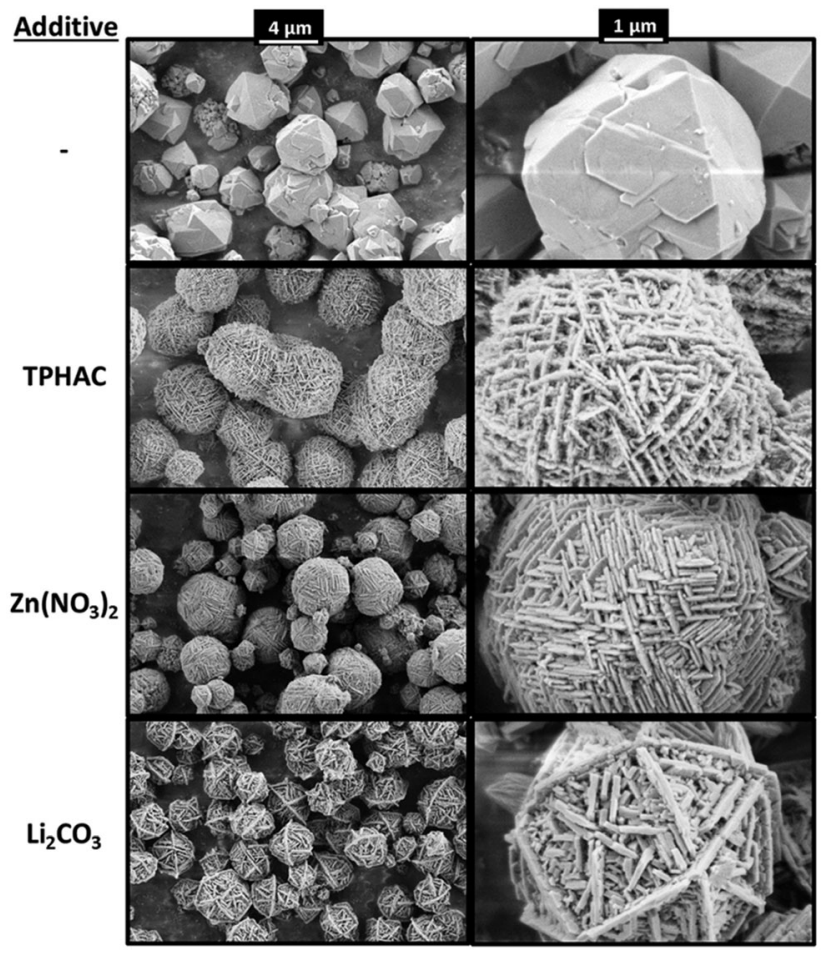

Fig. 1 SEM images of zeolite particles obtained in the absence (top row, $X$ conv.) and presence of different additives (organosilane TPHAC and two inorganic salts) in the synthesis mixture of FAU-type zeolite $\mathrm{X}$.

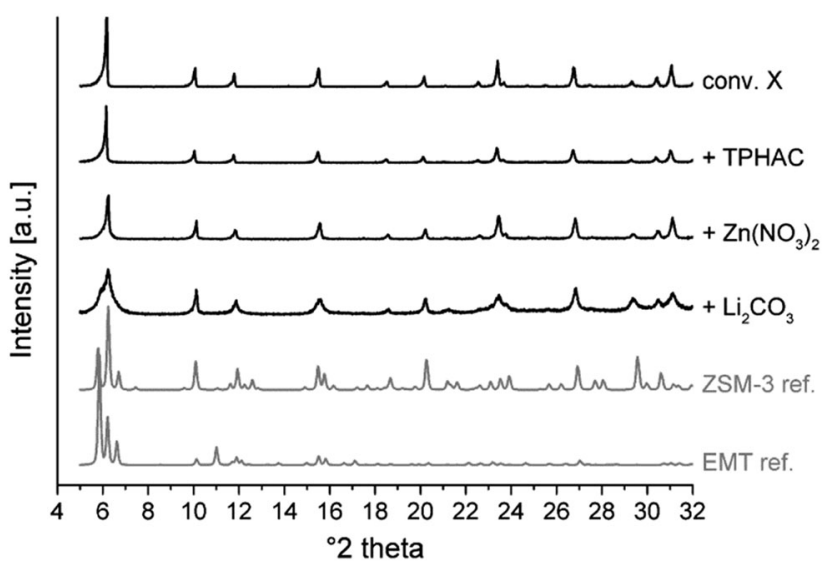

Fig. 2 XRD patterns of zeolite samples obtained in the absence (conv. X) and presence of zinc nitrate and lithium carbonate; for comparison purpose the XRD result of the sample from syntheses with the organosilane template TPHAC is also given.

sample, it should be present at least in very small TEM-visible amounts in order to enable the formation of the layer-like morphology, as already reported for the mesoporous layer-like zeolite X obtained in the presence of organosilanes. ${ }^{11}$

In contrast to syntheses with the mesopore template TPHAC, ${ }^{9}$ layer-like zeolite X produced in the presence of inorganic salts should not exhibit intracrystalline mesoporosity. The mesopore volume found in these samples through nitrogen physisorption (Fig. S1 and Table S1 in the ESI $\dagger$ ) originates most probably from 
the interlayer space within the platelet assemblies, which is even more pronounced in the sample synthesized in the presence of lithium carbonate due to its more open platelet arrangement. In contrast, we assume that the layer-like morphology of the sample synthesised in the presence of zinc nitrate is only present at the outer parts of the zeolite particles whereas a compact zeolite core could be the reason for the higher textural similarity with conventional zeolite $\mathrm{X}$ (lower mesopore volume, higher micropore volume).

In addition, for the samples synthesized in the presence of zinc nitrate and lithium carbonate, the influence of varying salt amounts on the structure and morphology evolution was investigated on the basis of SEM and XRD measurements (Fig. S2-S5, $\mathrm{ESI} \dagger)$. Increasing amounts of zinc nitrate and lithium carbonate in the synthesis mixture led to increasingly pronounced layerlike growth of the zeolite structure. In the case of increasing amount of zinc nitrate, the crystallisation rate was slowed down, which resulted in higher amounts of amorphous material remaining after similar crystallisation time while the FAU-type zeolite structure was formed in all cases. A very small content of XRD-visible EMT was only found for the highest zinc nitrate amount of $0.44 \mathrm{~mol} \mathrm{Zn}$ per $\mathrm{mol} \mathrm{Al}_{2} \mathrm{O}_{3}$ (Fig. S3, ESI $\dagger$ ). In contrast, in the case of lithium carbonate addition, a layer-like crystal morphology was always accompanied by XRD-visible EMT/ZSM-3 portions in the sample. $\mathrm{Li}^{+}$seems to strongly support twinning. Accordingly, increasing amounts of lithium carbonate in the synthesis mixture resulted in increasing tendency to form the ZSM-3 intergrowth structure as well as byproducts of zeolites A and its structural twin ZK-5 (Fig. S5, ESI $\dagger$ ), while the crystallisation rate was not significantly slowed down in this case.

In conclusion, it was shown that FAU-type zeolite $\mathrm{X}$ with layerlike morphology cannot only be obtained with organic growth modifiers like the organosilane TPHAC but also by using simple inorganic salts like zinc nitrate and lithium carbonate during synthesis. Using inorganic salts as morphology modifiers does not require complicated organic preparations nor postsynthetic calcination or template extraction, which is not only economically but also ecologically very attractive. In contrast to syntheses with zinc nitrate, the presence of lithium carbonate supports the formation of FAU/EMT intergrowth structures like ZSM-3 in larger extent, which leads to different particle morphologies and different durations for complete crystallisation, i.e. with zinc nitrate in the range of weeks compared to one day with lithium carbonate. From these observations different modes of morphology modifying action of zinc and lithium cations, respectively, seem likely. To investigate this phenomenon in more detail should be a future task. In general, crystallisation in the presence of certain inorganic salts might be a new concept also for changing the morphology of other zeolite structures, especially when twin structures exist.

This work was financially supported by the German Research Foundation through the Cluster of Excellence "Engineering of Advanced Materials". Furthermore, the authors would like to acknowledge the Erlangen Catalysis Resource Center (ECRC) at the University of Erlangen-Nuremberg for technical support.

\section{Notes and references}

1 C. H. Christensen, K. Johannsen, E. Törnqvist, I. Schmidt, H. Topsøe and C. H. Christensen, Catal. Today, 2007, 128, 117.

2 X. Zhang, D. Liu, D. Xu, S. Asahina, K. A. Cychosz, K. V. Agrawal, Y. Al Wahedi, A. Bhan, S. Al Hashimi, O. Terasaki, M. Thommes and M. Tsapatsis, Science, 2012, 336, 1684.

3 J. Perez-Ramirez, C. H. Christensen, K. Egeblad, C. H. Christensen and J. C. Groen, Chem. Soc. Rev., 2008, 37, 2530.

4 K. P. Möller and T. Bein, Chem. Soc. Rev., 2013, 42, 3689.

5 M. Choi, K. Na, J. Kim, Y. Sakamoto, O. Terasaki and R. Ryoo, Nature, 2009, 461, 246.

6 S. Mintova, J.-P. Gilson and V. Valtchev, Nanoscale, 2013, 5, 6693.

7 R. J. Davis, J. Catal., 2003, 216, 396.

8 W. Vermeiren and J.-P. Gilson, Top. Catal., 2009, 52, 1131.

9 A. Inayat, I. Knoke, E. Spiecker and W. Schwieger, Angew. Chem., Int. Ed., 2012, 51, 1962.

10 D. Mehlhorn, A. Inayat, W. Schwieger, R. Valiullin and J. Kärger, ChemPhysChem, 2014, 15, 1681.

11 M. Khaleel, A. J. Wagner, K. A. Mkhoyan and M. Tsapatsis, Angew. Chem., Int. Ed., 2014, 53, 9456.

12 O. G. Nik, B. Nohair and S. Kaliaguine, Microporous Mesoporous Mater., 2011, 143, 221.

13 G. Kokotailo and J. Ciric, Adv. Chem. Ser., 1971, 101, 109.

14 C. I. Round, C. D. Williams, K. Latham and C. V. A. Duke, Chem. Mater., 2001, 13, 468.

15 C. I. Round, C. D. Williams and C. V. A. Duke, Chem. Commun., $1997,1849$.

16 L. Wang, S. Sang, S. Meng, Y. Zhang, Y. Qi and Z. Liu, Mater. Lett., 2007, 61, 1675.

17 J. Perez-Pariente, V. Fornes, J. A. Martens and P. A. Jacobs, Stud. Surf. Sci. Catal., 1988, 37, 123.

18 J. M. Newsam, M. M. J. Treacy, D. E. W. Vaughan, K. G. Strohmaier and W. J. Mortier, Chem. Commun., 1989, 493. 